\title{
Introducing Childhood Cultures in Transformation
}

\author{
Elin Eriksen Ødegaard and Jorunn Spord Borgen
}

\begin{abstract}
In this introductory chapter we present how the book open the transformative landscape on childhood, both within educational institutions, such as kindergartens and primary schools and outside of them like family and cultural arenas like media, health and cultural arenas.
\end{abstract}

\section{Keywords}

cultural studies of childhoods - best interest of the child - right to participation and the right for protection - Nordic glance on transforming childhoods sustainability

\section{Introduction}

Around the world, organisations, researchers and individuals in and outside of politics have been and still are, inspired by the United Nations Convention on the Rights of the Child (UNCRC) (United Nations, 1989) and more recently the adoption of the 2030 Agenda, which includes the Sustainable Development Goals (SDGs) (UN, 2015, 2017). These global policy documents commonly advocate for the best interests of children and hope to put an end to inequality and injustice, protect the most vulnerable and secure life on planet earth.

Both agendas clearly outline the world and future we want, but children, families and educators often experience uncertainty related to the paradox of the gap between vision and practice. In this book we provide rich descriptions, constructive critique and recommendations for transformative research and practices. The UNCRC was declared in 1989 and reflect ideas of children and childhoods and the world views at the time it was drafted (1979-1989). Many of these ideas and world views still stand, but time calls for new reflections, empirical descriptions and knowledge as provided in this book. 
This book combines discussions, empirical research contributions and new methodological and philosophical perspectives on research within the theme of societal and cultural conditions for modern-day children between $\mathrm{o}$ and 18 years of age, accompanied by pointers to improve the future of these children. Special attention is directed to the conceptualisation of children and childhood cultures, the missing voices of the infant and the fragile child, as well as the paradoxes and transformations identified during times of globalisation and change. Paradoxically, children and young people can behave as adults when searching the internet for inspiration, knowledge and entertainment. While the experts who wrote the UNCRC wrote their drafts on typewriters, today both children and adults live in a new reality of technology and multiple worlds of learning possibilities that sometimes makes children more knowledgeable than adults (Veermann, 2014). Available information, opportunities for agency are not necessarily the problem in all occasions since given agency and voice does not take away the complexity for children and young people. Both children and adults face dilemmas and uncertainty when trying to figure out what is the best choice for them.

Childhood can be seen as a sheltered world unto itself, but the realities of a diverse society, an increasing awareness of the impact of climate change and health concerns due to pandemics have given rise to an entirely new range of childhood experiences. An often-forgotten dimension in child and youth studies is that childhood, the experience of being a child and education itself essentially form a temporal, geographical and generational phenomenon (Alanen, 2001; Massey, 2005; Uprichard, 2008; Kraftl, 2020). In an age of globalisation, the boundaries between cultures are blurred, and the relationship between them becomes important (Lee, 2020).

The past three decades in which the UNCRC has been operative have been a period with much discussion about the different constructions of children and childhood (Crowly, 2020; James \& James, 2004). Understanding the child while also understanding society are two sides of a coin. The authors of this book share the perspective that 'being' and 'becoming' are not in fact conflicting discourses and, therefore, will consider them together. When the child is seen as both 'being and becoming' the agency that child has in the world can increase (Uprichard, 2008).

A key outcome of the new social studies of childhood is that children are seen as active social agents who participate in the creation of knowledge and daily experience of childhood (Uprichard, 2008, p. 9). From this perspective, which is also the perspective of the authors of this book, children are seen as future agents. These perspectives have had increasing international recognition (World Organization for Early Childhood Education, 2017; Samuelsson, 
$\mathrm{Li}, \& \mathrm{Hu}, 2 \mathrm{2019})$. The general intellectual, ethical and cultural climate, what we call the zeitgeist of our time, will create conditions for what is considered right and wrong, while relational, material, geographical and bodily senses and impressions will shape conditions for what children can or cannot experience and learn (Hackett, 2016; Rautio \& Stenvall, 2019). A few of these experiences will be very similar to the experiences children have had for generations, regardless of where they are born and live, while others are more or less timeand place-specific, such as whether children spend time in institutions in China or in Nordic Countries or whether they play (un)supervised outdoors or (un)supervised indoors with touchscreens, virtual reality games, etc.

During the 2oth century, efforts to develop successful global policies for children have been concluded with the UNCRC and ratification by most countries, but there are still many bumps in the road as the authors of this book remind us. This book is an argument for why we have to reconsider the future, bringing in relational and contextual knowledge when considering the best interests of a child. The rich descriptions and contributions take us far beyond the discourse of school and educational success, as seen in so many projects dealing with children and youth in education. This book reorients the view of children and young people being merely objects of education. The collection of chapters open the transformative landscape on childhood, both within educational institutions, such as kindergartens and primary schools and outside of them like family and cultural arenas like media, health and cultural arenas.

UNCRC (United Nations, 1989) holds two central children's rights that need to be balanced: the right to participation and the right for protection. The Convention stresses that every child has rights, whatever their ethnicity, gender, religion, language, abilities, etc., and on these grounds, the Convention must be seen as a whole as all the rights are linked and important. According to Lucy Smith, ${ }^{1}$ the General Measurements of Implications (2003, no 5) underlines four principles as general for the whole Convention: article 1 about how the best interests of the child shall be a primary consideration in all actions concerning children, article 2 about non-discrimination, article 6 about children's right to life and the maximum extent of possible survival and development and article 12 about children's rights to express their views freely in 'all matters affecting the child. These views are being given due weight. The latter is the most radical, along with articles 13 to 16 regarding freedom of expression, 
freedom to be of any or no religion, the right to meet with friends and to join groups and the right to privacy (Smith, 2008).

The authors of this book consider the right to relax and play (article 31) and the right to freedom of expression (article 13) of equal importance as the right to be safe from violence (article 19), the right to guidance from adults (article 5) and the right to education (article 28) - which must develop every child's personality, talents and abilities to the full (article 29). ${ }^{2}$ However, for any child and adult, these rights have the potential to be paradoxical. In spite that UNCRC is being implemented in laws and regulations in most countries, crime, suppression and unjust decisions are present in many children's lives, also in the name of the child's best interest. What is 'the best interest of the child' is not a question with a straightforward answer. A parent and teacher will easily disagree with children in certain questions. Children's voices on these matters will simply collide when meeting cultural expectations. These are problems that will be illuminated and elaborated on in this book.

Because difficult and impossible decisions need to be made, without parental or child consent, societies, experts and professionals need ethical guidelines. What is considered the child's best interest is essentially a personal and individual norm that experts, professionals or parents use as a guide (according to their own values) when considering the suitability and appropriateness of approaches to making choices or decisions. Determining the child's best interest requires a value judgement - what is an interest, whose interest, what is the best interest in this situation, time and place? Although the child's interests should be the sole focus for concern, children's interest cannot be decided without taking into consideration, validating or scrutinise the information coming from those who make decisions on their behalf. The common assumption is that parents seek their child's best interest, informed and supported by experts and professionals (Dan, 2018). However, experts and professionals does not by mandate relate to their personal norms, but rather to their position as their child's best expert and advocate. Unfortunately, experts can give the wrong advice based on prejudice, lack of sensitiveness, professionals can have bad judgment and parents can harm their children in the name of their best interest. Furthermore, many countries and territories are not able to follow guidelines provided by the UNCRC and, for example, secure education for all. UNESCO (2019) reported that despite the considerable progress on access to education and participation over the past years, 262 million children and youth aged 6 to 17 were still out of school in 2017, and despite rapid technological changes presenting opportunities and challenges, the learning environment, capacities of teachers and quality of education have not kept pace. Refocused efforts are needed to improve 
learning outcomes for the full life cycle, especially for women, girls and marginalised people in vulnerable settings (UNESCO, 2019). Conflict of interest exists, and since the public has different values and norms, policies regarding child culture and education will also be areas of dispute and disagreement (Urban, 2018). Agency and participation have been key concepts over these last 30 years with the convention, and research has been occupied with the relation between social structure and the individual social actor (Vuorisalo, Raittila, \& Rutanen, 2018) within sociological and interdisciplinary frameworks. The extent to which these studies have had an impact on policy, family and institutional lives and practice varies (Gradovski et al., 2019).

The history of the UNCRC's adoption and the continuous debate over children's rights and the best interests of a child must never be regarded as set in stone. Researchers suggest that children live in diverse conditions and that present concerns may move beyond the context of the UNCRC and pave the way for rethinking the entirety project of children's rights (Quennerstedt, Robinson, \& I'Anson, 2018). This book intends to contribute towards such a dialogue. The chapters will present analytical arguments and empirical examples of paradoxes, inconsistencies, tensions and contradictions that exist in children's lives and point to possible impacts for the future.

\section{A Nordic Glance on Transforming Childhoods}

The original driving forces for a Nordic glance on childhoods were cultural and geographical. It is important to rethink what a Nordic glance entails, and this book will provide a multifocal glance that goes beyond geographical and cultural boundaries. In Nordic research, the question of 'Nordic added' value is often raised but is difficult to articulate (NordForsk, 2011). The creation of knowledge and the use of knowledge will always be intimately tied to networks. Knowledge production is therefore a social process. In small countries like Nordic ones, researchers act on an international level, concurrently, Nordic researchers act in Nordic networks, and childhood, child culture and educational research have a particularly strong standing, according to NordForsk ${ }^{3}$ (NordForsk, 2011, 2018). The Nordic-added value from this book will be new scientific knowledge with examples of how the UNCRC is used in research, how it motivates and justifies research and how the UNCRC has become a selfevident mandate for a researcher to consider. The contributions are a result of a longstanding cooperation and exchange, some of which is funded by Nordic ministries and research councils in Nordic countries. 
This book was initiated by researchers connected to the BIN-Norden Child Culture Research Network. This network was established in the 1970s and connects almost 300 researchers. For the last $25^{-50}$ years, researchers in the fields of child culture, educational science, sociology and media have focused on studying and viewing children and young people in their own rights in order to grasp their perspectives and then both critique and analyse the child culture industry, child culture professions and the instrumentalisation of childhood (Borgen \& Ødegaard, 2015). The editors of this volume have organised three conferences in the Nordic countries in cooperation with the University of Copenhagen (in 2014), the Norwegian School of Sport Sciences, and the Western Norway University of Applied Sciences (in 2016), and the University of Jyväskylä and the Finnish Society of Childhood Studies (in 2018). Alongside these conferences, a three-year project entitled New Nordic childhoods - Paradoxes and transformation was supported by the Nordic Council of Ministers (Nordplus ${ }^{4}$ ). The dialogues in these conferences and network meetings have challenged the idea of one Nordic childhood and one dominant discourse (Borgen \& Ødegaard, 2015). The papers for these conferences include examples of paradoxes within the Nordic welfare system and examples of newly changing Nordic childhoods. This book will analyse a selection of these papers and add several more to provide a collection of new discussions and ideas regarding local transformation in a global society. Paradoxes are a common feature in these works, some of which include taking parenthood seriously, having higher birth rates than more traditional family cultures, making legislations for parents to spend longer periods of time with their infants, having institutionalised childhood, encouraging children to be independent from an early age, and experiencing what some would call a modernisation of the family. The editors of the book worked as a leading team of the BIN-Norden Child Culture Research Network from 2012-2018.

Even if the studies presented in this book are derived from a Nordic network, some of them present international global-oriented perspectives. Even if the Nordic model and the Nordic welfare system are often internationally associated with 'happy childhoods', time for self-organised play and nature activities (Aasgaard, Bunge, \& Roos, 2018), this book does not claim a Nordic identity; these authors agree upon the new concept of childhood as both local and global simultaneously.

Several interesting topics are presented in the chapters of this book in an aim to identify the zeitgeist of our recent times. The book provides rich empirical 
descriptions and new knowledge to help readers understand the conditions of the children and how they live their lives in the twenty-first century, how childhoods vary and how culture matters in their specific contexts. All chapters provide up-to-date knowledge and discussions on methodologies and philosophies in childhood studies and beyond, and discuss findings and relate to articles in the UNCRC. In doing so, the book highlights the complexity of cultural studies of childhood in an inter-disciplinary manner.

Chapter 2, "From the Century of the Child to the Century of Sustainability", written by Liv Torunn Grindheim, Jorunn Spord Borgen and Elin Eriksen Ødegaard show how perceptions and mobilisation of the UNCRC has changed over time. The authors present significant transformations of understandings of childhood in the Nordic context over the past 120 years, pointing to the challenges that researchers face when doing research for problem-solving in achieving the rights of children, especially children's right to be heard, right to protection and right to play. They argue for transdisciplinary research designs to approach paradoxes and ambivalences they have identified.

Children's intellectual capacity and right to be heard in matters that concern them have been increasingly acknowledged and given more importance both in research on children and in childrearing. In Chapter 3, "On Equal Terms? On Implementing Infants' Cultural Rights", Pauline von Bonsdorff argues that a slight 'adultocentrism', that is, the modelling of children on adults, runs through the UNCRC, (with the examples of articles 13, 14 and 29), that diminishes its relevance and applicability, especially when it comes to infants.

In Chapter 4, "Children with Severe, Multiple Disabilities: Interplaying Beings, Communicative Becomings", Kristin Vindhol Evensen discusses how these children's transitions between interplay and communication, embodiment and expression, subjectivity and objectivity, expressivity and interpretation and being and becoming are understood and described in research and included in UNCRC articles 12 and 13. This analysis could help inform experts, professionals and families about how to best communicate and listen to children with severe disabilities. The chapter also contributes to the discussion on challenges studying the cognitive discourse of human rights in line with the arguments put forward in Chapter 3 by Pauline von Bonsdorff.

The UNCRC upholds the view that children are competent, strong, active, participatory, meaning-makers and fellow citizens who have the right to be involved in decisions that affect them and who have the freedom to express their thoughts and opinions. This sentiment is echoed in Chapter 5, "Spaces for Transitions in Intergenerational Childhood Experiences", written by Czarecah Oropilla. This chapter explores where and how space is given to listen to children, especially in inter-generational interactions, through a literature review on inter-generationality across institutions and contexts and through the use 
of multi-modal methodologies. Oropilla also points to how research and practice that take the opinions of both children and adults into consideration will further the Un's 203o Sustainable Development Goals and Agenda.

In Chapter 6, "Managing Risk and Balancing Minds: Transforming the Next Generation through 'Frustration Education', Ida Marie Lyså describes the phenomenon 'frustration education' in contemporary urban China. She presents the societal transformations that have taken place in China over the last decades and explains how these changes have been accompanied by changes to the perceived challenges of children in contemporary and future Chinese society. The chapter gives a rich and unique description of how the staff in kindergartens is trying to build future citizens by specific pedagogies. Here, the best interests of children are presented as being intertwined with the best interests of society as a whole.

Children's freedom to choose and food practices in everyday life is examined in Chapters 7 and 8. In Chapter 7, "Children's Food Choices during Kindergarten Meals", Hege Wergedahl, Eldbjørg Fossgard, Eli Kristin Aadland and Asle Holthe examine children's food choices during lunch and how these choices contribute to children's dietary intake. In Chapter 8, "Children, Food and Digital Media: Questions, Challenges and Methodologies", Karen Klitgaard Povlsen, Stinne Gunder Strøm Krogager, Jonatan Leer and Susanne Højlund Pedersen discuss the results of their study on children in sixth and seventh grade home economics classes involving the use of digital media in relation to their everyday routines and food practices. This chapter argue for that the digital media offer new possibilities of inviting children to express their views freely as the article 12 of the UNCRC proposes.

The cultural context of childhood is changing. Conditions on children's agency and cultural participation are being negotiated among adults and children and constructed in new ways. For example, Chapters 9 and 10 discuss risk and resistance as being negotiable. In Chapter 9, "Children at Risk' in Public Health Policy: What Is at Risk?", Jorunn Spord Borgen, Gro Rugseth and Wenche Bjorbækmo examine how children's future health risks arise in the Nordic context and how such risks are outlined as problematic in two Norwegian health policy documents. The chapter provides insight into the conception of risk and its dependence on the various interpretations of the phrase "in the best interest of the child" (United Nations, 1989, art. 3). It also challenges the understanding of children's right to express their views freely in "all matters affecting the child" (art. 12).

What is considered suitable or desirable behaviour for children is under constant negotiation in day-to-day interactions between children and adults. In Chapter 10, "Childish' beyond Age: Reconceptualising the Aesthetics of 
Resistance", Susanne C. Ylönen explores the concept of 'aesthetic sublation', that is, a performative mode of meaning-making that seeks to degrade an object (Ylönen, 2016; Korsmeyer, 2011). She discusses this phenomenon as a form of resistance related to inter-generational negotiations. As such, the chapter relates to UNCRC article 31, which presents the child's right to engage in play and recreational activities as long as they are "appropriate to the age of the child".

Liv Torunn Grindheim analyses how actors can be traced in an intra-activity in Chapter 11: "Approaching Agency in Intra-Activities". With reference to childhood studies and the UNCRC, that legalise children's right to express their views, she claims that it is time to challenge the dichotomy between agency and structure. By considering material-discursive forms of agency, she demonstrates how actors can be traced in an activity involving Polydron (toy for construction). She claims that Polydron, children, teachers, families, the economy, play, learning, and the position of mathematics in education emerge as actors in one sense or another. Thus, the space for agency between actors and structures can be identified and widened.

Anja Maria Pesch, in Chapter 12: 'Studying Families' and Teachers' Multilingual Practices and Ideologies in Kindergartens: A Nexus Analytic Approach", discusses which insights an applied nexus analytic approach may contribute with to the field of childhood studies. Based on ethnographic fieldwork in two kindergartens (one in Norway and one in Germany), she argues that the analysis shed light on the complexity of intersections of linguistic practices and the study of it. The practices and choices made by parents and teachers involve values of specific languages and codes and create conditions for the children's own linguistic practice. A question deriving from this complexity is then which forms of linguistic practice may be in the best interest of multilingual children.

In Chapter 13, "Studies of Child Perspectives in Methodology and Practice with 'Osallisuus' as a Finnish Approach to Children's Cultural Participation", Liisa Karlsson discusses the methodology and practices used in research on children's perspectives and participation as a cultural phenomenon, specifically in Finland. Conducting research on children can be justified in terms of children's rights and learning needs, as noted in this chapter with reference to article 12, UNCRC.

Chapter 14, by Jorunn Spord Borgen and Elin Eriksen Ødegaard explores the future of education as articulated by a group of children and a group of child experts selected by the authors, highlighting the similarities of their perspectives. The chapter suggests some qualities that a sustainable future would require in relation to the UNCRC articles 28 and 29 . The chapter is especially tied to Chapter 2, which states that, when designing sustainability research, 
the best interest of the child should be considered. This requires a transformative research agenda. An informed discussion, as provided in this book, will be a necessary starting point in reimagining children's rights for the twenty-first century.

\section{Notes}

1 Lucy Smith (1943-2013) was a member of the U.N. Committee on the Rights of the Child, and as an expert she monitored and reported on the implementation of the United Nations Convention on the Rights of the Child. Smith was also Norway's first female (full) professor of law (1987) and served as rector of the University of Oslo (1993-1998).

2 These statements are paraphrases from the UNICEF website: https://www.unicef.org.uk/ what-we-do/un-convention-child-rights/

3 NordForsk is an organisation under the Nordic Council of Ministers that provides funding for and facilitates Nordic cooperation on research and research infrastructure.

4 Nordplus, the Nordic Council of Ministers' program in the area of lifelong learning, financed a Nordic master's course on Nordic Childhoods in Transformation that were embedded in these three conferences and organised as sessions and research tasks for master students.

\section{References}

Aasgaard, R., Bunge, M. J., \& Roos, M. (2018). Nordic childhoods 1700-196o: From folk beliefs to Pippi Longstocking. Routledge.

Alanen, L., \& Mayall, B. (2001). Conceptualising child-adult relationships. Routledge. https://www.researchgate.net/publication/278406453_Alanen_L_B_Mayall_ eds_2001_Conceptualizing_child-adult_relations_London_RoutledgeFalmer

Borgen, J. S., \& Ødegaard, E. E. (2015). Barnekultur som forskningsfelt - et interdisiplinært vitenskapelig emne [Children's culture as a research field - An interdisciplinary scientific topic], BARN, 33(3-4), 5-17.

Crowly, A. (2020). Global report 2019 Progress towards ending corporal punishment of children. Retrieved April 19, 2020, from http://endcorporalpunishment.org/ wp-content/uploads/global/Global-report-2019.pdf

Dan, B. (2018). The child's best interest: Ethical guide or ideology? Developmental Medicine \& Child Neurology, 6o(1), 4. doi:10.1111/dmcn.136o8

General Comment No.5. (2003). General measures of implementation of the convention on the rights of the child (Arts. 4, 42 and 44, para. 6). Retrieved April 24, 2020, from https://resourcecentre.savethechildren.net/node/9689/pdf/general_comment_ no_5_crc.pdf

Gradovski, M., Ødegaard, E. E., Rutanen, N., Sumsion, J., Mika, C., \& White, E. J. (2019). The first 1000 days of early childhood: Becoming (Vol. 2). Springer Singapore. 
Hackett, A. (2016). Young children as wayfarers: Learning about place by moving through it. Children \& Society, 30(3), 169-179.

James, A., \& James, A. L. (2004). Constructing childhood: Theory, policy, and social practice. Palgrave Macmillan.

Kraftl, P. (2020). After childhood: Re-thinking environment, materiality and media in children's lives. Routledge.

Lee, Y. Y. (2020). Beyond the dichotomy: Engaging a deeper dialogue about our interdependent futures between the western and non-western horizon. ECNU Review of Education, 3(1), 16o-163. https://doi.org/10.1177/2096531120905210

Massey, D. B. (2005). For space. Sage.

NordForsk. (2011). Rethinking Nordic added value in research. Nordic Council of Ministries. https://www.norden.org/en/publication/rethinking-nordic-addedvalue-research

NordForsk. (2018). NordForsk strategy 2019-2022. Nordic Council of Ministries. https://www.norden.org/en/publication/nordforsk-strategy-2019-2022

Quennerstedt, A., Robinson, C., \& I'Anson, J. (2018). The UNCRC: The voice of global consensus on children's rights? Nordic Journal of Human Rights, $36(1), 38-54$. doi:10.1080/18918131.2018.1453589

Rautio, P., \& Stenvall, E. (2019). Social, material and political constructs of arctic childhoods: An everyday life perspective. Springer.

Samuelsson, I. P., Li, M., \& Hu, A. (2019). Early childhood education for sustainability: A driver for quality. ECNU Review of Education, 2(4), 369-373. https://doi.org/10.1177/ 2096531119893478

Smith, L. (2008). FNs konvensjon om barnets rettigheter [UN's Convention on the Rights of the Child]. In N. Høstmælingen, E. S. Kjørholt, \& K. Sandberg (Eds.), Barnekonvensjonen. Barns rettigheter i Norge. Universitetsforlaget.

UNCRC. (1989). United Nations Convention on the Right of the Child. Retrieved April 21, 2020, from https://downloads.unicef.org.uk/wp-content/uploads/2010/05/

UNCRC_united_nations_convention_on_the_rights_of_the_child.pdf? ga $=2.259582415 \cdot 454887985 \cdot 1587459175-44770236.1585716747$

United Nations. (2015). Transforming our world: The 2030 agenda for sustainable development (A/Res/44/25). UN General Assembly. https://www.ohchr.org/CH/

ProfessionalInterest/Pages/CRC.aspx

United Nations Educational, Scientific and Cultural Organization (UNESCO). (2017). Education for sustainable development goals: Learning objectives. United Nations Educational, Scientific and Cultural Organization.

United Nations Educational, Scientific and Cultural Organization (UNESCO). (2019). Special edition: Progress towards the sustainable development goals. UN Secretary General. 
Uprichard, E. (2008). Children as 'being and becomings': Children, childhood and temporality (Report). Children \& Society, 22(4), 303.

Urban, M. (2018). (D)evaluation of early childhood education and care? A critique of the OECDs international early learning study. In L. P. Michel Matthes, C. Clouder, \& B. Heys (Eds.), Proving the quality of childhood in Europe (Vol. 7, pp. 91-99). Alliance for Childhood European Network Foundation.

Veerman, P. (2014). The aging of the UN Convention on the Rights of the Child. In M. Freeman (Ed.), The future of children's rights. Brill | Nijhoff. https://doi.org/10.1163/ 9789004271777_004

Vuorisalo, M., Raittila, R., \& Rutanen, N. (2018). Kindergarten space and autonomy in construction - Explorations during team ethnography in a Finnish kindergarten. Journal of Pedagogy, 9(1), 45-64. doi:10.2478/jped-2018-00o3

World Organization for Early Childhood Education. (2017). Higher investment for Early Childhood Care and Education (ECCE): Declaration of the 6gth assembly and world conference of OMEP. http://worldomep.org/index.php?hCode $1 / 4$ POLICY_O3_O4 